\title{
Avaliação dos intangíveis: uma aplicação em capital humano
}

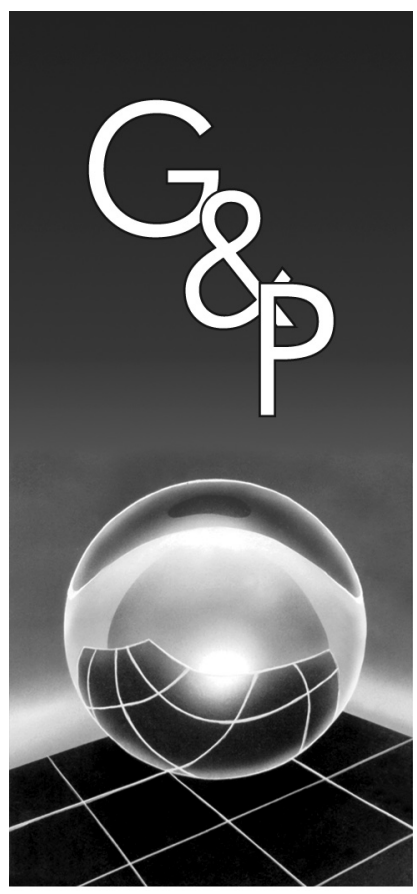

\author{
Vera do Carmo Comparsi de Vargas \\ Paulo Maurício Selig \\ Dalton Francisco de Andrade \\ José Luis Duarte Ribeiro
}

\section{Resumo}

Este artigo tem por objetivo apresentar uma proposta de avaliação dos intangíveis, implementada no capital humano $(\mathrm{CH})$. O desenvolvimento desta proposta resultou na criação de uma medida quantitativa, a Escala de Medida do Desempenho nos Intangíveis (EMDI), determinada com os modelos matemáticos da Teoria da Resposta ao Item (TRI) para o construto definido como o desempenho das organizações nos intangíveis. O conjunto de itens produzido aborda o $\mathrm{CH}$, com ênfase no processo de desenvolvimento, especificamente nas atividades de treinamento, desenvolvimento, educação e planejamento/avaliação. Os dados levantados junto a uma amostra de 203 empresas associadas à Federação de Indústrias de Santa Catarina (FIESC) permitiram estabelecer a EMDI com quatro níveis interpretados para $o \mathrm{CH}$, fornecendo novos conhecimentos tanto sobre os intangíveis quanto sobre o desempenho das empresas.

Palavras-chave: Medição de intangíveis. Gestão de intangíveis. Capital intelectual. Capital humano. Teoria da resposta ao item.

\section{Introdução}

As mudanças econômicas das últimas décadas têm gerado uma sociedade na qual o principal recurso é o conhecimento. A expressão capital intelectual (CI) tem sido usada na literatura para se referir aos intangíveis. O primeiro a usar o termo CI foi o economista Galbraith em 1969 (ANDRIESSEN, 2004b). De acordo com Stewart, em 1958, este termojá tinha sido empregado para explicar a avaliação do mercado para as ações de pequenas empresas voltadas para atividades científicas. Para essas organizações, o elemento mais importante talvez fosse o seu CI. $\mathrm{Na}$ imprensa de negócios, o primeiro artigo sobre CI foi publicado por Stewart em 1991. Após essa data, inúmeras publicações têm abordado o tema, visto que, freqüentemente, o valor de empresas bem sucedidas no mercado de ações é superior ao valor dos ativos apresentados nos relatórios financeiros (STEWART, 2002). Sveiby relatou seus métodos em 1989. Em 1995, a Skandia, empresa sueca, apresentou o primeiro relatório público em CI. Em 1997, a publicação de diferentes livros versando sobre CI ajudou a criar a grande comunidade de acadêmicos e práticos no assunto (EDVINSSON; MALONE, 1997;
ROOS et al., 1997; STEWART, 1997; SVEIBY,1997). A partir daí, houve uma explosão de atividades, conforme demonstrado nas revisões feitas por Petty e Guthrie (2000), Ayuso (2003), Kaufmann e Schneider (2004) e Roos, Pike e Fernström (2004).

Organizações pioneiras que iniciaram na prática de medir o CI e publicar suas experiências bem sucedidas nesse campo obtiveram um diferencial no mercado e, com isso, também atingiram vantagem competitiva. Exemplo disso são as empresas suecas Skandia e Celemi (BRENNAN, 2001; GUTHRIE; PETTY, 2000). Os pesquisadores têm investigado o uso dos sistemas de mensuração e divulgação dos intangíveis nos diversos empreendimentos e negócios. O exemplo das pioneiras tem sido utilizado como benchmarking para avaliar o grau de importância atribuída a esse tema, por meio dos relatórios publicados informando o estado do CI (APRIL; BOSMA; DEDLON, 2003).

Pesquisas empíricas com o objetivo de verificar a experiência das empresas em divulgar seu CI têm sido realizadas e publicadas. Por exemplo, na Dinamarca 
e Austrália (ENGSTRÖM; WESTNES; WESTNES, 2003), nos Estados Unidos, Canadá, Alemanha, Reino Unido, Japão e Coréia do Sul (ABEYSEKERA; GUTHRIE, 2004b), na Austrália (GUTHRIE; PETTY, 2000), na Irlanda (BRENNAN, 2001), no Sri Lanka (ABEYSEKERA; GUTHRIE, 2004b), na África do Sul (APRIL; BOSMA; DEDLON, 2003), na Itália (BOZZOLAN; FAVOTTO; RICCERI, 2003), no Brasil e Estados Unidos (KAYO, 2002), na Ásia, Europa e Oriente Médio (PABLOS, 2002), na Espanha (PABLOS, 2003), na Malásia (BONTIS; KEOW; RICHARDSON, 2000) e em Taiwan (TSAN; CHANG, 2005).

Andriessen (2004b) concluiu que a perspectiva dos intangíveis capacita para a exposição e a explicação das mudanças no modo de se comportarem a economia, as organizações individuais e os indivíduos. Na opinião desse autor, a perspectiva dos intangíveis também é capaz de identificar novos problemas organizacionais e oferecer novas soluções para a administração, conforme assegura o grupo de práticos e pesquisadores que estudam o CI.

Essas constatações constituíram o primeiro momento no qual se estabeleceu a consciência da importância dos intangíveis para as organizações (MARR; CHATZKEL, 2004). Atualmente, esta área entra numa fase de consolidação após um período no qual predominou a proposição de diversos novos métodos para sua administração e/ou avaliação (ANDRIESSEN, 2004a). No próximo estágio, os práticos e os acadêmicos devem demonstrar a relevância do CI como uma disciplina para alcançar metas estratégicas e melhorar o nível de desempenho das organizações. Há necessidade de progredir no entendimento de como o valor pode ser gerado e capturado, usando uma perspectiva dos intangíveis bem como o reconhecimento de que há múltiplos modos de conhecimento e diferentes modelos de CI (CHATZKEL, 2004).

Devido às características do atual contexto econômico, marcadas pelo dinamismo, tem-se a necessidade de constantemente estar criando novas abordagens e indicadores para acompanhar o desempenho dos negócios. Uma tendência nos trabalhos publicados no campo do CI tem sido a adoção de um enfoque para realçar as vantagens competitivas que distinguem as empresas e que lhes proporcionam um diferencial no mercado. Por outro lado, há também a necessidade de se estabelecer um padrão de medição ou benchmarking, que possibilite fazer comparações, tanto entre diferentes intangíveis quanto entre diferentes empresas, além de propiciar o acompanhamento de suas evoluções ao longo do tempo.

A partir dessas observações, resume-se a problemática para o presente artigo: como realizar a avaliação dos intangíveis de modo que seja possível tanto atender à necessidade de se estabelecer uma medida que permita fazer comparações entre intangíveis e empresas quanto contemplar as características que oferecem vantagens competitivas às empresas? Este artigo é uma demonstração prática da criação de uma escala de medida na qual se localizam os itens de intangíveis e as empresas, numa mesma unidade de medição padronizada (e, por isso, comparáveis entre si), determinada por meio dos modelos matemáticos da teoria da resposta ao item (TRI) para o modelo teórico de avaliação dos intangíveis, proposto por Vargas (2007).

O modelo conceitual (VARGAS, 2007) prevê que a implementação seja feita nas abordagens teórica, experimental e analítica. A primeira desenvolve teoricamente o construto, definido como o desempenho nos intangíveis, para o qual se quer desenvolver o instrumento de medida, permitindo sua operacionalização em itens. A segunda define os procedimentos para a aplicação do instrumento-piloto e da coleta dos dados. A terceira estabelece os modelos e métodos de análises dos dados por meio da teoria da resposta ao item (TRI).

\section{Capital intelectual}

Estudos empíricos mostram que há relações consistentes entre os elementos do capital intelectual (CI) - capital humano, capital estrutural e capital de clientes - com o desempenho organizacional (BONTIS, 1998). Bontis, Keow e Richardson (2000) verificaram que o capital humano $(\mathrm{CH})$ é importante independentemente do tipo de setor (manufatura ou serviços). Wang e Chang (2005) concluíram que, apesar de o CH ter um impacto indireto no desempenho, possui um impacto direto nos outros elementos do CI - capital de inovação e de processo - que, conseqüentemente, afeta também o desempenho. Para esses autores, o CH é o principal fator em que a administração deveria colocar o maior esforço (TSAN; CHANG, 2005).

As três categorias, reunindo capital de clientes, humano e organizacional, conforme pesquisadores do CI, estão fundamentadas na premissa de que as empresas não podem criar conhecimento por si mesmas sem a iniciativa dos indivíduos (EDVINSSON; MALONE, 1998, BONTIS, 1998, 2002, 2004; WANG; CHANG, 2005). Os intangíveis da categoria de $\mathrm{CH}$, "capacidade de agir em diversas situações para criar tanto tangíveis como intangíveis", estão inseridos nos membros da organização (SVEIBY, 1998, p. 11). O CH incluiria não apenas competências humanas, tais como habilidades, know-how e inovação, mas também atitude humana. Criar e compartilhar conhecimento são atividades intangíveis que não podem ser supervisionadas nem exigidas. Elas acontecem somente quando as pessoas cooperam voluntariamente. O que as organizações podem fazer é oferecer uma cultura de aprendizagem, infra-estrutura e incentivos apropriados para gerar e disseminar conhecimento (TSAN; CHANG, 2005). 
As avaliações de desempenho referentes a CI vêm sendo realizadas por meio de inúmeros indicadores. $\mathrm{O}$ Quadro 1 ilustra os enfoques dados pelos pesquisadores nas suas abordagens para as sugestões de indicadores. Alguns enfoques são apresentados por mais de um pesquisador, porém o enfoque humano é comum a todas essas abordagens.

Embora uma categoria de intangível não exista sem o suporte de outra, entende-se que o $\mathrm{CH}$ é importante para a existência das demais categorias, bem como para a integração e sinergia entre os componentes dos intangíveis. Assim, para a viabilização operacional deste artigo, optou-se por uma aplicação restrita ao $\mathrm{CH}$.

\section{Capital humano}

A origem do termo capital humano é atribuída ao economista Theodore Schultz, que se preocupava com as situações precárias das nações subdesenvolvidas. $\mathrm{Na}$ opinião dele, os conceitos econômicos tradicionais não tratavam desse problema. Ele alegava que o bem-estar dos pobres não dependia da terra, dos equipamentos ou da energia, e sim do conhecimento (FITZ-ENZ, 2001).

Para Edvinsson e Malone (1998, p. 31), "toda capacidade, conhecimento, habilidade e experiência individual dos empregados e gerentes estão incluídos no termo capital humano". Esses autores formulam várias questões que poderiam ser utilizadas para captar a dinâmica de uma organização inteligente em um ambiente competitivo em mudança, bem como a criatividade e a inovação organizacionais. O Quadro 2 apresenta uma síntese das diversas definições propostas por alguns autores.

Como ilustrado acima, em virtude da diversidade de definições, neste artigo, optou-se por trabalhar com a agregação de valor propiciada pelo $\mathrm{CH}$.

\subsection{Valor agregado pelo capital humano}

A agregação de valor por meio do $\mathrm{CH}$ se dá pela "contribuição efetiva ao patrimônio de conhecimentos que permite à organização manter suas vantagens competitivas no tempo" (DUTRA, 2002, p. 126).

$\mathrm{O}$ processo de medição do valor agregado pelo $\mathrm{CH}$, seguindo a proposta apresentada em Fitz-enz (2001), abrange seis etapas: planejamento; incorporação; manutenção; desenvolvimento; retenção; e avaliação. Cada uma dessas atividades tem definições conceituais, funções e ferramentas gerenciais próprias, além de algumas particularidades, como, por exemplo, a incorporação (que compreende recrutamento e seleção). Em muitas empresas, esta é uma atividade terceirizada. Por entender que, de um modo geral, o processo de desenvolvimento é uma atividade realizada por qualquer empresa, em maior ou menor intensidade, dependendo da importância atribuída pela organização ao seu $\mathrm{CH}$, foi escolhido esse tópico para a aplicação da proposta deste artigo.

Pesquisa realizada por Antunes e Martins (2005), em grandes empresas brasileiras, buscou responder a questões envolvendo o entendimento do conceito de CI pelos gestores; elementos que o representam; investimentos; e sistemas de indicadores. Os resultados mostram que os gestores associam o conceito de $\mathrm{CI}$ às pessoas da organização, e o elemento que recebe maior investimento é

Quadro 1. Abordagens estruturais para as sugestões de indicadores de CI.

Pesquisadores/autores

Edvinsson e Malone (1998)

Sveiby (1998)

Padoveze (2000)

Cowi (2000)

Cumby e Conrod (2001)

Brennan e Connel (2000)

Guthrie e Petty (2000)

Liebowitz e Suen (2000)

Koch e Leitner (2000)

Allee (2000)

\section{Enfoques das abordagens}

Capital humano, capital organizacional e capital de cliente.

Estrutura externa, interna e competência das pessoas, distintas nas áreas de crescimento e renovação, eficiência e estabilidade.

Capital humano, clientela e relacionamentos e capital organizacional.

Clientes e mercado, empregados e organização, em três áreas: recursos, processos e resultados.

Indicadores financeiros, ciência, empregados, alianças e mercado.

Recursos humanos, clientes/relacional, tecnologia, processos/estrutural.

Capital interno (estrutural), capital externo (relacional/clientes) e competência dos empregados (capital humano).

Indicadores para: obtenção de valores, capital do cliente, capital estrutural, criação de valor e capital humano.

Três tipos de capital: humano, estrutural e relacional além de pesquisa independente, contratos de projetos de pesquisa e resultados.

Competência humana, estrutura interna, relacionamento externo, identidade corporativa, cidadania social e saúde ambiental. 
Quadro 2. Definições para $\mathrm{CH}$ e seus respectivos autores.

\begin{tabular}{|c|c|}
\hline Autores & O que é CH \\
\hline Bontis (1998) & $\begin{array}{l}\text { Capacidade coletiva da empresa para extrair as melhores soluções do conhecimento de seus } \\
\text { colaboradores. O conhecimento que cada empregado possui. }\end{array}$ \\
\hline Bontis e Fitz-enz (2002) & Conhecimento, talento e experiência dos empregados. \\
\hline Bontis, Keow e Richardson (2000) & Combinação de: herança genética, educação, experiência e atitudes sobre a vida e os negócios. \\
\hline Brooking (1996) & Habilidades, capacidades e perícia, capacidade de resolver problemas e estilos de liderança. \\
\hline Davenport (2001) & Capacidade, comportamento e empenho inseridos na dimensão tempo. \\
\hline Edvinsson e Malone (1998) & $\begin{array}{l}\text { Capacidade, conhecimento, habilidade, experiência, criatividade e poder de inovação de todos os } \\
\text { membros de uma organização, assim como valores, cultura e filosofia da empresa. }\end{array}$ \\
\hline Fitz-enz (2001) & $\begin{array}{l}\text { Inteligência, energia, atitude normalmente positiva, confiabilidade, responsabilidade, aptidão, } \\
\text { imaginação, criatividade, prudência, sensatez, espírito de equipe e orientação a metas. }\end{array}$ \\
\hline Roos (2003) & Competência, atitude e agilidade intelectual dos indivíduos que trabalham em uma organização. \\
\hline Stewart (1998) & $\begin{array}{l}\text { Capacidades que os clientes esperam das pessoas com as quais tratam na empresa. } \mathrm{O} \text { ativo mais } \\
\text { importante de uma organização. Fonte de inovação e renovação. }\end{array}$ \\
\hline Sveiby (1998) & $\begin{array}{l}\text { Capacidade do funcionário de agir em diversas situações para criar tanto ativos tangíveis como } \\
\text { intangíveis. }\end{array}$ \\
\hline
\end{tabular}

o treinamento e desenvolvimento de pessoal. Análise de conteúdo realizada pelos pesquisadores relativos aos modelos e tipos de indicadores revela que, em 63,3\% das empresas, "encontram-se indicadores de acompanhamento do desempenho gerencial e indicadores específicos para a área de Recursos Humanos" (ANTUNES; MARTINS, 2005, p. 7).

$\mathrm{Na}$ literatura pesquisada, a denominação mais usual para a etapa do processo de desenvolvimento de pessoas é treinamento e desenvolvimento (T\&D). Mais recentemente o termo educação tem sido agregado à sigla, passando a ser treinamento, desenvolvimento e educação (TD\&E), conforme Borges-Andrade, Abbad e Mourão (2006). De um modo geral, o treinamento prepara a pessoa para o desempenho adequado no cargo ou na função específica, abrangendo uma formação de curto e médio prazo. O desenvolvimento prepara a pessoa, não apenas para o cargo ou para a função dentro da empresa, mas também para seu futuro, tanto dentro da empresa quanto fora dela, abrangendo uma formação educacional de médio e longo prazo. As definições dos três modos de expressar a aquisição de conhecimento TD\&E, visando o desenvolvimento profissional, são apresentadas com seus autores no Quadro 3.

Segundo Araújo (2006), o processo de TD\&E envolve quatro etapas: diagnose; planejamento; implementação; e avaliação. Em Dessler (2003), o processo de TD\&E ocorre em cinco passos: levantamento das necessidades; projeto instrucional; validação; implementação; e avaliação. Com base nesses autores, estabeleceu-se uma definição para as etapas de planejamento/avaliação como sendo o processo em que se faz o levantamento das necessidades da empresa e dos interesses dos participantes para programar eventos de treinamento, desenvolvimento e educação prevendo antecipadamente critérios de avaliação dos resultados esperados e determinação de custos benefícios dos programas.

\section{Teoria clássica de medida e teoria da resposta ao item}

\subsection{Teoria clássica de medidas}

"O uso do número na descrição dos fenômenos naturais constitui o objeto da teoria da medida" (PASQUALI, 1997, p. 29). Para Nunnally (1978), a medição consiste em procedimentos padronizados para atribuir números a objetos de modo a representar quantidades de atributos. $\mathrm{O}$ termo atributo indica que não se medem objetos e sim suas características. Essa distinção é importante, primeiro porque demonstra que a medição requer um processo de abstração. Um atributo diz respeito às relações entre objetos em uma dimensão particular. Em segundo lugar, para enfatizar que o interesse em uma característica específica é que leva a considerar a natureza do atributo antes de tentar medi-lo.

Pasquali (1997) apresentou três formas diferentes de mensuração: medida fundamental, medida derivada e medida por teoria. Medir por teoria consiste no procedimento de medir um atributo de outra natureza (um atributo hipotético: variável não diretamente observável) por meio de um outro atributo empírico (variáveis obser- 
Quadro 3. Definições para treinamento, desenvolvimento e formação profissional/educação.

\begin{tabular}{|c|c|}
\hline Autor & Definições para treinamento \\
\hline $\begin{array}{l}\text { Milkovich e Boudreau } \\
\text { (2000) }\end{array}$ & $\begin{array}{l}\text { Processo sistemático para promover a aquisição de habilidades, regras, conceitos ou atitudes que resul- } \\
\text { tem em uma melhoria da adequação entre as características dos empregados e as exigências dos papéis } \\
\text { funcionais. }\end{array}$ \\
\hline Chiavenato (2002) & $\begin{array}{l}\text { Processo educacional de curto prazo, aplicado de maneira sistemática e organizada, pelo qual as pessoas } \\
\text { aprendem conhecimentos, atitudes e habilidades em função de objetivos definidos. }\end{array}$ \\
\hline Stoner e Freeman (1999) & Processo destinado a manter ou melhorar o desempenho no trabalho atual. \\
\hline Boog (1994) & Educação que visa adaptar a pessoa a determinada atuação sistemática (profissional ou não). \\
\hline Dessler (2003) & $\begin{array}{l}\text { Conjunto de métodos usados para transmitir aos funcionários novos e antigos as habilidades necessárias } \\
\text { para o desempenho do trabalho. }\end{array}$ \\
\hline $\begin{array}{l}\text { Borges-Andrade, Abbad e } \\
\text { Mourão (2006) }\end{array}$ & $\begin{array}{l}\text { Eventos educacionais de curta e média duração compostos por subsistemas de avaliação de necessidades, } \\
\text { planejamento instrucional e avaliação que visam melhoria do desempenho funcional, por meio da criação } \\
\text { de situações que facilitem a aquisição, a retenção e a transferência da aprendizagem para o trabalho. }\end{array}$ \\
\hline \multirow[t]{2}{*}{ Araújo (2006) } & $\begin{array}{l}\text { Processo que oferece condições que facilitem a aprendizagem e a plena integração das pessoas na orga- } \\
\text { nização. }\end{array}$ \\
\hline & Definições para desenvolvimento profissional \\
\hline $\begin{array}{l}\text { Milkovich e Boudreau } \\
\text { (2000) }\end{array}$ & $\begin{array}{l}\text { Processo de longo prazo para aperfeiçoar as capacidades e motivações dos empregados a fim de torná- } \\
\text { los futuros membros valiosos da organização. O desenvolvimento inclui não apenas o treinamento, mas } \\
\text { também a carreira e outras experiências. }\end{array}$ \\
\hline Stoner e Freeman (1999) & Processo destinado a desenvolver as habilidades necessárias para futuras atividades de trabalho. \\
\hline Boog (1994) & $\begin{array}{l}\text { Educação que visa ampliar e aperfeiçoar a pessoa para seu crescimento - em determinada carreira ou em } \\
\text { sua evolução pessoal. }\end{array}$ \\
\hline Dutra (2002) & Capacidade para assumir atribuições e responsabilidades em níveis crescentes de complexidade. \\
\hline \multirow[t]{2}{*}{$\begin{array}{l}\text { Borges-Andrade, Abbad e } \\
\text { Mourão (2006) }\end{array}$} & $\begin{array}{l}\text { Conjunto de experiências e oportunidades de aprendizagem, proporcionadas pela organização e que } \\
\text { apóiam o crescimento pessoal do empregado sem, contudo, utilizar estratégias para direcioná-lo a um } \\
\text { caminho profissional específico. }\end{array}$ \\
\hline & Definições para formação profissional/educação \\
\hline Chiavenato (2002) & $\begin{array}{l}\text { Educação profissional institucionalizada ou não, que visa preparar e formar a pessoa para o exercício de } \\
\text { uma profissão, em determinado mercado de trabalho. }\end{array}$ \\
\hline $\begin{array}{l}\text { Borges-Andrade, Abbad e } \\
\text { Mourão (2006) }\end{array}$ & $\begin{array}{l}\text { Conjuntos de eventos educacionais de média e longa duração que visam à formação e qualificação pro- } \\
\text { fissional contínuas dos empregados. }\end{array}$ \\
\hline
\end{tabular}

váveis). A função da teoria é garantir a legitimidade da operação, tratando do problema da representação - a questão da validade da medida. A operação empírica de medir as ações observáveis representa a medida do construto (PASQUALI, 1997).

O construto de interesse neste artigo é o desempenho das organizações nos intangíveis, com foco no desenvolvimento do capital humano (DCH). Os conceitos abrangem o treinamento, desenvolvimento e educação (TD\&E) e planejamento/avaliação. As categorias teóricas desses conceitos podem ser expressas por variáveis observáveis. $\mathrm{O}$ conjunto de itens ou indicadores associados aos intangíveis constitui um modo de medição indireta, por meio de instrumentos calibrados. O instrumento de medida - conjunto de itens - deve apresentar validade, confia- bilidade (PASQUALI, 2003; ANASTASI; URBINA, 2000), unidimensionalidade e independência local. A unidimensionalidade é entendida como a homogeneidade do conjunto de itens, isto significa que se deseja medir apenas uma dimensão dominante, compreendida pelo construto de interesse: o desempenho das organizações nos intangíveis. A independência local quer dizer que as respostas dadas por uma empresa a um determinado item não dependem das respostas dadas a outros itens (ANDRADE; TAVARES; VALLE, 2000; EMBRETSON; REISE, 2000).

\subsection{Teoria da resposta ao item}

A teoria da resposta ao item (TRI) é uma estrutura estatística para se fazer escalas de mensuração por meio 
de modelos matemáticos que estabelecem uma relação entre a probabilidade de um respondente dar uma resposta certa a um item e seus construtos na área de conhecimento avaliada. Essa teoria vem sendo empregada desde a década de 80 na avaliação educacional, inicialmente nos Estados Unidos, e atualmente se expande para outras áreas e países. No Brasil, o Sistema Nacional de Ensino Básico (SAEB) e Sistema de Avaliação de Rendimento Escolar do Estado de São Paulo (SARESP) empregam a TRI para comparar o desempenho de alunos de diferentes séries em uma única escala de conhecimento (ANDRADE; TAVARES; VALLE, 2000). Aplicações da TRI em outras áreas no Brasil são, por exemplo, a análise das práticas da Gestão da Qualidade Total (ALEXANDRE et al., 2002) e a avaliação de intangíveis nas organizações (VARGAS, 2007).

Na teoria clássica de medidas (TCM), as análises são feitas com a soma dos escores do conjunto de itens como um todo. Na TRI, o interesse principal está na resposta, afirmativa ou não, que um respondente obtém para cada item, e não no escore bruto (BAKER, 2001). A TRI possui diversas vantagens sobre os métodos da TCM por desenvolver medidas equivalentes entre conjuntos de itens e respondentes. Algumas limitações teóricas da TCM são encontradas em Hambleton, Swaminithan e Rogers (1991). Embretson e Reise (2000) fazem um paralelo demonstrando as vantagens da TRI sobre a TCM.

Uma medida do construto, compreendido como o desempenho das organizações nos intangíveis, seria estabelecida por meio de um conjunto de itens ou indicadores dessa área. Cada item mede algum aspecto particular do construto de interesse. Do ponto de vista técnico, os itens teriam respostas fornecidas conforme a realidade da empresa avaliada (ou unidade de negócio). Uma suposição é que cada empresa respondendo a um conjunto de itens possua implicitamente alguma quantia de intangíveis. Assim, pode-se considerar que cada empresa tenha um valor numérico, um escore, que a coloque em algum lugar na escala de medida de desempenho nos intangíveis - EMDI. Este escore de desempenho nos intangíveis será denotado por $\theta$ (teta). A cada nível de $\theta$, existirá uma probabilidade da empresa com aquele $\theta$ dar uma resposta afirmativa para o item. Esta probabilidade será denotada por $\mathrm{P}(\theta)$ (BAKER, 2001).

\subsubsection{Modelos da teoria da resposta ao item}

Modelar as relações entre os desempenhos nos intangíveis e as empresas, por meio de um conjunto de itens, é a base para a proposição do modelo de avaliação dos intangíveis. Para isso, utilizam-se os modelos matemáticos da TRI, os quais proporcionam a precisão e o rigor necessários à teoria (BAKER, 2001). Há vários modelos propostos na literatura pesquisada (VAN DER LINDEN; HAMBLETON, 1997; ANDRADE; TAVARES; VALLE,
2000; EMBRETSON; REISE, 2000, BAKER, 2001, BAKER; KIM, 2004, OSTINI; NERING, 2006).

O modelo logístico de 3 parâmetros (ML3) é o mais geral, entre os modelos dicotômicos. A proporção de respostas para atingir as metas estabelecidas para o $i$-ésimo item dos intangíveis, fornecida por empresas com desempenho $\theta_{\mathrm{j}}$, é interpretada como uma probabilidade, dada por $\mathrm{P}\left(\mathrm{U}_{\mathrm{ij}}=1 / \theta_{\mathrm{j}}\right)$. A Figura 1 representa a relação entre $\mathrm{P}\left(\mathrm{U}_{\mathrm{ij}}=1 / \theta_{\mathrm{j}}\right)$ e os parâmetros do modelo, chamada curva característica do item (CCI).

O modelo é não linear, isto é, o desempenho não tem uma relação linear com a probabilidade de possuir o intangível. Essa relação tem o formato de uma curva em "S" com inclinação e deslocamento na escala de medição conforme os parâmetros dos itens. O parâmetro $b_{i}$ representa a dificuldade para possuir o i-ésimo item dos intangíveis, interpretado como a localização da função da resposta ao item ao longo do eixo horizontal, $\theta$, e está na mesma unidade de medida da EMDI. O parâmetro $c$ é uma probabilidade (assume valores entre 0 e 1) e não depende da escala. $\mathrm{O}$ parâmetro $\mathrm{a}_{\mathrm{i}}$ representa o poder de discriminação do i-ésimo item dos intangíveis, com valor proporcional à inclinação da curva no ponto $b_{i}$. $O$ parâmetro $\mathrm{a}_{\mathrm{i}}$ representa a declividade da curva; quando aumenta $\mathrm{a}_{\mathrm{i}}$, o grau de inclinação da função da resposta ao item aumenta (ANDRADE; TAVARES; VALLE, 2000).

Neste artigo, não se admitirá a resposta ao acaso, isto é, $\mathrm{c}=0$. Assim, o ML3 é simplificado para o modelo logístico de 2 parâmetros (ML2), expresso pela Equação 1:

$$
P\left(U_{i j}=1 / \theta_{j}\right)=\frac{1}{1+\exp \left\{-a_{i}\left(\theta_{j}-b_{i}\right)\right\}}
$$

Com: $\mathrm{i}=1,2,3, \ldots, \mathrm{p}$ (itens propostos para capturar os atributos configurando os intangíveis); $j=1,2,3, \ldots, n$ (representando $\mathrm{n}$ empresas que compõem a amostra);

Em que: $\mathrm{U}_{\mathrm{ij}}$ : variável dicotômica que assume o valor 1 (um) quando a j-ésima empresa possui o i-ésimo intangível, ou assume 0 (zero) quando a j-ésima empresa não possui o i-ésimo intangível; e $\theta_{\mathrm{j}}$ : representa o valor

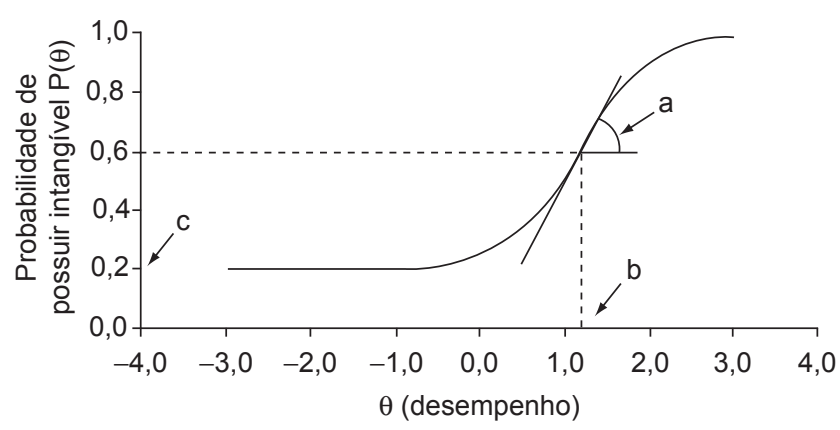

Figura 1. Curva característica do item (CCI). (ANDRADE; TAVARES; VALLE, 2000, p. 11). 
do construto, isto é o nível de desempenho da j-ésima empresa quanto aos seus intangíveis.

$$
P\left(U_{i j}=1 / \theta_{j}\right), a_{\mathrm{i}} \text { e } \mathrm{b}_{\mathrm{i}} \text { definidos anteriormente }
$$

A estimação dos parâmetros dos itens, a (discriminação), b (dificuldade) e $\theta$ (parâmetro dos respondentes) é feita pelo método da máxima verossimilhança, aplicando os processos iterativos do algoritmo Newton-Raphson e "Scoring" de Fisher. O parâmetro $\theta$ teoricamente pode assumir qualquer valor entre $-\infty \mathrm{e}+\infty$. Assim, precisa-se estabelecer uma origem e uma unidade de medida para a definição da escala. Esses valores são escolhidos de modo a representar, respectivamente, o valor médio e o desvio-padrão dos desempenhos dos respondentes da população em estudo. Usualmente utiliza-se a escala com média igual a zero $(\mu=0)$ e desvio-padrão igual a um $(\sigma=1)$ que é representada na escala $(0,1)$. Nos modelos da TRI, os parâmetros $\theta$ e b são estimados na mesma unidade de medida estabelecida para a escala. Nesta escala, esperamos que os valores estimados para os parâmetros $\theta$ e b variem entre -3 e 3 , isto é, entre 3 desvios-padrão acima e abaixo da média. Em termos práticos, é usual estabelecer os valores dos parâmetros na escala $(0,1)$ e posteriormente fazer uma transformação para outra escala qualquer, mantendo as relações de ordem existentes entre seus pontos. Com relação ao parâmetro $a$, esperam-se valores entre 0 e 2 , sendo que os valores mais apropriados de a seriam aqueles maiores do que 0,8. Quando os valores estimados para o parâmetro a são menores que 0,8 , tem-se um item com pouco poder de discriminação, que pode ser visualizado no formato mais achatado da CCI. Quando os valores estimados para o parâmetro a são maiores ou igual a 0,8 , tem-se um item que discrimina bem e, nesse caso, a CCI tem um formato mais íngreme (ANDRADE; TAVARES; VALLE, 2000).

Os modelos da TRI fornecem funções de informação que permitem analisar o erro padrão de medida, quando se estima o desempenho de uma empresa nos intangíveis. A função de resposta ao item (FRI); função de resposta ao teste (FRT); função de informação do item (FII); função de informação do teste (FIT); e erro padrão de medida (EPM) refletem a qualidade dos itens individuais e do conjunto de itens, como um todo (BAKER; KIM, 2004). Os modelos matemáticos das funções podem ser encon- trados em Embretson e Reise (2000) e Andrade, Tavares e Valle (2000).

\section{Aplicação}

Empregando a técnica de validação - validade de conteúdo - construiu-se o conjunto de itens com base nas definições teóricas apresentadas para o TD\&E e planejamento/avaliação, seguindo orientação de Pasquali (1997, 1998, 2003). As definições teóricas foram operacionalizadas e transformadas no conjunto de 33 itens. Os itens foram submetidos a uma avaliação da sua qualidade em duas etapas: a análise dos especialistas e o pré-teste. Os especialistas foram cinco professores do Departamento de Administração da Universidade Federal de Santa Catarina, com formação em Administração e especialização em recursos humanos $(\mathrm{RH})$. O pré-teste foi realizado com uma pequena amostra composta por micro, pequenas, médias e grandes (MPMG) empresas de Florianópolis-SC.

A população-alvo, na pesquisa realizada, constituiu-se das empresas associadas à Federação das Indústrias do Estado de Santa Catarina - FIESC. O levantamento de dados foi feito por e-mail usando o serviço de informação - Guia Web SC da FIESC. Uma carta apresentando os objetivos do trabalho foi encaminhada às empresas juntamente com o pedido de colaboração para que o responsável da área de RH ou gestão de pessoas (GP) respondesse ao conjunto de itens. O índice de respostas foi de $8,1 \%$, obtendo-se uma amostra de 203 empresas, no período de 13 de setembro até 18 de outubro de 2006, conforme a Tabela 1 .

\section{Análises}

A consistência interna do conjunto de itens foi verificada por meio do alfa de Cronbach, determinado com uso do software Statistica 6.0, obtendo-se 0,96, superior a 0,75 que é considerado satisfatório (NUNNALLY, 1978).

A análise da unidimensionalidade foi realizada pela análise fatorial de informação plena, técnica mais apropriada para dados categorizados, utilizando o programa computacional TESTFACT. O resultado obtido apresentou o primeiro fator responsável por explicar $44,0 \%$ da variabilidade geral dos dados e o segundo fator explicando $9,0 \%$, mostrando que o primeiro fator explica quase cinco vezes

Tabela 1. População e amostra.

\begin{tabular}{ccccc}
\hline $\begin{array}{c}\text { Tamanho da } \\
\text { empresa }\end{array}$ & $\begin{array}{c}\text { Número de } \\
\text { empregados }\end{array}$ & $\begin{array}{c}\text { Quantidade de empresas para as } \\
\text { quais foram enviados e-mails }\end{array}$ & $\begin{array}{c}\text { Empresas } \\
\text { respondentes }\end{array}$ \\
\hline Micro & 8 a 19 & 157 & 21 \\
Pequenas & 20 a 99 & 1.611 & 93 \\
Médias & & 100 a 499 & 592 & 68 \\
Grandes & & mais de 500 & 142 & 21 \\
& Total & & 2.502 & 203 \\
\hline
\end{tabular}


mais da variação do conjunto de itens do que o segundo fator. Com este resultado, pode-se dizer que o conjunto de dados tem um fator dominante, fato que justifica a utilização de um modelo unidimensional da TRI. Comprovada a unidimensionalidade, tem-se também satisfeita a suposição de independência local (ANDRADE; TAVARES; VALLE, 2000; EMBRETSON; REISE, 2000).

A análise dos itens por meio da TRI foi realizada empregando a Equação 1 e usando o software BILOG. Para o presente artigo, foi necessário adequar os dados obtidos com o instrumento de coleta, formulado para cinco categorias de respostas, recodificando-os para duas categorias. Consideram-se, neste caso, as categorias de respostas $\geq 3$ ("bastante praticado" e "muito praticado") como sendo a resposta "sim" e as categorias de respostas $\leq 2$ ("não praticado", "quase nada praticado" e "pouco praticado") como sendo a resposta "não".

$\mathrm{O}$ processo de análise foi realizado em três fases. $\mathrm{Na}$ primeira fase, foram feitas a entrada e a leitura dos dados, obtendo-se a correlação bisserial. Na segunda fase, estimaram-se os parâmetros dos itens: a (discriminação) e b (dificuldade). Na terceira fase, estimaram-se os parâmetros dos respondentes, o $\theta$.

Os resultados obtidos para a correlação bisserial mostraram todos os itens com valor superior a 0,44 . O usual é aceitar valores acima de 0,3 para a correlação bisserial (SOARES, 2005). Assim, todos os itens do conjunto foram validados. $\mathrm{Na}$ segunda fase, a aplicação do algoritmo Newton-Raphson e o método "Scoring" de Fisher mostraram que houve convergência dos dados, necessária para continuar o processo de estimação dos parâmetros dos respondentes.

\subsection{Estimação dos parâmetros dos itens}

As estimativas obtidas para o parâmetro de discriminação dos itens variaram entre 0,938 e 3,471, determinadas na escala $(0,1)$. Esses resultados mostraram que os itens discriminam bem, logo, todos os itens permaneceram para o prosseguimento das análises. As CCIs dos itens podem ser visualizadas no Apêndice 1. Os itens 6 e 10 (com fundo em realce cinza escuro) apresentaram suas CCIs mais achatadas (valores de $\mathrm{a}=0,949 \mathrm{e} \mathrm{a}=0,938$ ). Os itens 22 e 26 apresentaram suas CCIs mais íngremes (valores de $\mathrm{a}=2,767$ e a $=3,471$ ). Quanto maior o valor de a, maior é a quantia de informação que o item possui para o nível da escala na qual ele se localiza (parâmetro b).

Os valores do parâmetro b são estimados na mesma unidade de medida determinada pelas estimativas dos parâmetros dos respondentes $(\theta)$, isto é, na escala $(0,1)$. Isso significa que os itens podem ser localizados na escala de desempenho e, por isso, podem ser comparáveis entre si. Quanto maior o valor de b, maior o nível de desempenho necessário para a empresa possuir o referido item de intangível e vice-versa.

\subsection{Informação do conjunto de itens - função de informação do teste}

A função de informação do item (FII) indica a quantidade de informação que um item contém em todos os pontos ao longo da EMDI. Uma característica importante das FIIs é que, se somadas, elas fornecem a função de informação do teste (FIT) e desta é determinado o erro padrão de medida (EPM). Assim, pode-se verificar o grau de precisão do conjunto de itens para as várias faixas da escala de medição do desempenho. A Figura 2 apresenta a FIT e o EPM para o conjunto de itens.

A linha contínua exibe a FIT e é analisada pela escala vertical esquerda. A FIT atinge maior informação no nível da média até um desvio-padrão na escala de desempenho. O EPM (linha pontilhada) é o inverso, ou seja, quanto maior informação, menor o erro e maior a precisão. A leitura do EPM é feita na escala vertical direita. Assim, o menor erro padrão também está no intervalo de 0 a 1 da escala de desempenho. O EPM aumenta, à medida que se desloca na EMDI para a esquerda, chegando a 1,85. Para os valores mais altos - à direita na EMDI -, o erro padrão se aproxima de 0,4 . Isso significa que o conjunto de itens utilizado nesta pesquisa é válido onde o EPM é baixo, isto é, para os níveis médio e imediatamente acima, na EMDI.

\subsection{Criação da escala de medida de desempenho nos intangíveis ou escala de conhecimento}

Usando a Equação 1 e as estimativas dos parâmetros, determinaram-se as probabilidades acumuladas em cada nível da escala $(0,1)$. Arbitrariamente, atribuem-se outros valores quaisquer para a média e o desvio-padrão, mantendo as relações de ordem existentes entre seus pontos (ANDRADE; TAVARES; VALLE, 2000). Um dos objetivos da transformação da escala $(0,1)$ para outros valores é o de facilitar sua utilização pelo usuário não familiarizado com valores negativos. Uma possível transformação poderia ser imaginada para valores entre 0 e 100 . No entanto, esses valores não foram utilizados porque a

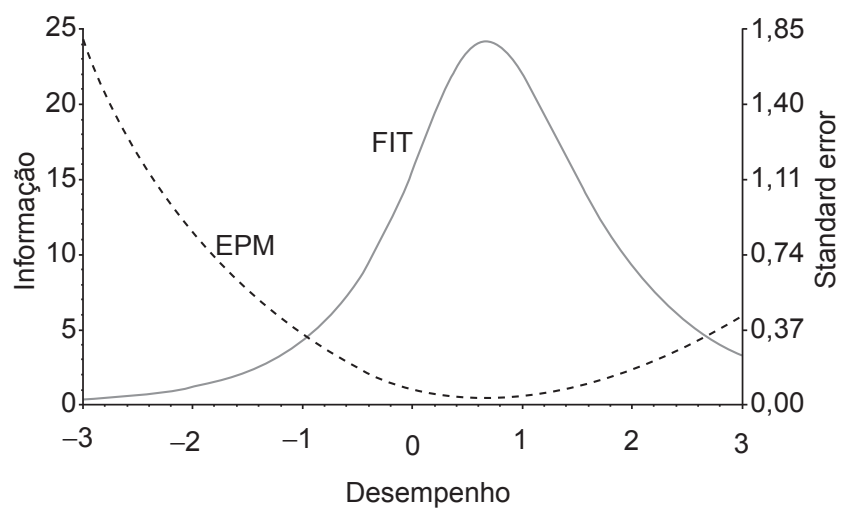

Figura 2. Função de informação do teste (FIT em linha cheia) e erro padrão de medida (EPM em linha pontilhada). 
escala definida de 0 a 100 poderia vir a ser associada pelos usuários às variações em percentuais, o que não corresponderia às interpretações da TRI. Neste artigo, se propõe a transformação para uma escala com a média igual a 500 e o desvio-padrão igual a 50. Assim, constrói-se a EMDI $(500,50)$ empregando as Equações 2, 3, 4 e 5 a seguir:

$$
\begin{gathered}
\theta^{*}=50 \times \theta+500 \\
b^{*}=50 \times b+500 \\
a^{*}=a / 50 \\
P(U \mathrm{i}=1 / \theta)=P\left(U \mathrm{i}=1 / \theta^{*}\right)
\end{gathered}
$$

Em que: a, b e $\theta$ são os parâmetros estimados da escala $(0,1) ; a^{*}, b^{*}$ e $\theta^{*}$, e são os parâmetros resultantes da transformação para a escala $(500,50)$.

A probabilidade de uma empresa possuir um certo item de intangível é sempre a mesma, independentemente da escala utilizada para medir seu desempenho, ou ainda, o desempenho de uma empresa é invariante à escala de medida (ANDRADE; TAVARES; VALLE, 2000).

As probabilidades de possuir um determinado item de intangível são acumuladas na escala de modo que, quanto mais à direita da escala um item se localizar, maior é o desempenho requerido da empresa para possuir tal item. As probabilidades são acumuladas nos níveis da escala de acordo com os parâmetros estimados e mostram os níveis na EMDI em que o analista pode fazer as interpretações gerenciais. Para caracterizar cada nível da escala, os itens são denominados de âncoras. Para ser âncora, um determinado item necessita satisfazer, simultaneamente, três condições. Tomando dois níveis consecutivos, $\mathrm{X}$ e $\mathrm{Y}$, com $\mathrm{X}<\mathrm{Y}$, um determinado item é âncora para o nível Y se satisfazer (Equações 6, 7 e 8):

$$
\begin{gathered}
P(U=1 \mid \theta=Y) \geq 0,65 \\
P(U=1 \mid \theta=X)<0,50 \\
P(U=1 \mid \theta=Y)-P(U=1 \mid \theta=X) \geq 0,30
\end{gathered}
$$

Os doze itens que atenderam essas três condições encontram-se nos níveis 550 e 600 da EMDI. Além desses, outros dez itens que obtiveram resultados aproximados para satisfazer essas condições também foram considerados para auxiliar na interpretação da escala. Com esses itens, obtêm-se os significados para a gestão de pessoas, com a EMDI interpretável em quatro níveis.

Na Tabela 2, apresentam-se todos os itens desenvolvidos para este artigo: os parâmetros dos itens (a e b) transformados na escala 500, 50; as probabilidades acumulas de determinada empresa, com certo nível de desempenho, apresentar as práticas constantes em cada item de intangível; os níveis estabelecidos para a EMDI; e os itens âncoras (com realce em cinza).

O novo conhecimento criado para os intangíveis é obtido da interpretação dos níveis da escala. Assim, o nível 500 da EMDI é caracterizado pela prática de preparar adequadamente uma pessoa que está começando na empresa para o exercício de um cargo e oferecer condições que facilitem sua aprendizagem e plena integração na organização. Isto significa que, do conjunto de itens, essa prática é a mais comumente encontrada nas empresas pesquisadas. Pode-se concluir que as empresas com esse grau de desempenho possuem a prática constante nesse nível e não realizam as práticas que caracterizam os demais níveis acima desse.

As empresas localizadas no nível 550 da EMDI caracterizam-se por: formalizar políticas de incentivos financeiros para cursos técnicos profissionalizantes, oficinas, seminários, palestras, etc.; proporcionar aos seus colaboradores treinamentos técnicos e desenvolvimento gerencial, quando surge uma oportunidade; possuir centro próprio de treinamento e realizar programas de qualidade de vida no trabalho; priorizar o recrutamento interno e considerar os interesses e os objetivos dos colaboradores na participação dos programas; prever critérios de avaliação na fase de planejamento; fazer análise de custo benefício de cada programa; realizar de modo formal e informal a avaliação dos resultados alcançados; e executar melhorias a partir desses resultados. As empresas com grau de desempenho igual a 550 possuem as práticas constantes nesse nível, além das práticas que caracterizam o nível 500, mas não realizam as práticas dos níveis subseqüentes.

As empresas que alcançam o nível 600 na EMDI distinguem-se por apresentarem, além das práticas verificadas nos níveis anteriores, as seguintes características: são estruturadas para prever em orçamento anual os programas de desenvolvimento gerencial; possuem sistemas de divulgação interna das competências necessárias para cada cargo, bem como sistemas de avaliação de desempenho que fornece feedback aos colaboradores, recompensando-os por apresentarem melhoria nos seus desempenhos, tanto individual como por equipe; também fazem parcerias com instituições de ensino superior para ministrar educação continuada a seus colaboradores. As empresas localizadas nesse nível realizam todas as práticas, exceto aquelas que caracterizam o nível 650 da EMDI.

As empresas que chegam ao nível 650, além de possuir as práticas verificadas nos níveis anteriores, realizam parcerias com instituições de ensino superior para desenvolver programas personalizados de acordo com suas competências essenciais e contam com um sistema estruturado de administração de carreiras. As empresas localizadas nesse nível possuem todas as práticas relativas aos itens característicos do conjunto de itens. 
O valor estimado para o desempenho de cada empresa serve como um indicador para localizá-la na EMDI. A Figura 3 ilustra como as empresas participantes da pesquisa encontram-se localizadas na EMDI.

A Figura 3 mostra que $49,8 \%$ das empresas não realizam as práticas constantes no conjunto de itens, ou seja, não apresentam os intangíveis de DCH. Quase um terço do total da amostra, 31,0\%, tem os intangíveis relativos ao nível 500 da escala e não têm os demais intangíveis. Por volta de $17,7 \%$ das empresas possuem os intangíveis dos níveis 550 e 500, porém não possuem os intangíveis do nível 600 e seguinte. Apenas 1,0\% das empresas possui os intangíveis dos níveis 600, 550 e 500, mas não possui os intangíveis do nível 650 . Somente $0,5 \%$ do grupo de empresas possui todos os intangíveis relativos ao conjunto de itens desta pesquisa.

Os itens mais informativos, determinados com base na FII, são os mais apropriados para representar cada um dos

Tabela 2. Os itens e seus parâmetros na escala 500, 50; os níveis da EMDI e as probabilidades acumuladas.

\begin{tabular}{|c|c|c|c|c|c|c|c|c|c|c|}
\hline \multirow[t]{2}{*}{ Itens } & \multicolumn{2}{|c|}{ Parâmetros } & \multicolumn{8}{|c|}{ Níveis da EMDI - Escala $(500,50)$} \\
\hline & $\mathbf{a}$ & $\mathbf{b}$ & 350 & 400 & 450 & 500 & 550 & 600 & 650 & 700 \\
\hline 5-Treino inicial ou básico para recém che & 0,026 & & 0,07 & 0,21 & 0,49 & 0,77 & 0,92 & 0,98 & 0,99 & 1,00 \\
\hline $\begin{array}{l}\text { 26-Melhorias no planejamento e execução dos programas após } \\
\text { avaliações }\end{array}$ & 0,069 & 527,26 & 0,00 & 0,00 & 0,00 & 0,13 & 0,83 & 0,99 & 1,00 & 1,00 \\
\hline 22-Previsão de critérios para avaliar resultados dos programas & 0,055 & 521,49 & 0,00 & 0,00 & 0,02 & 0,23 & 0,83 & 0,99 & 1,00 & 1,00 \\
\hline 29-Prioridade para recrutamento interno & 0,029 & 496,19 & 0,01 & 0,06 & 0,21 & 0,53 & 0,83 & 0,95 & 0,99 & 1,00 \\
\hline 21-Consideração de interesses ou objetivos dos colaboradores & 0,040 & 510,77 & 0,00 & 0,01 & 0,08 & 0,40 & 0,82 & 0,97 & 1,00 & 1,00 \\
\hline 23-Análise do custo benefício no planejamento dos programas & 0,052 & 522,57 & 0,00 & 0,00 & 0,02 & 0,24 & 0,80 & 0,98 & 1,00 & 1,00 \\
\hline 14-Incentivos financeiros para oficinas, seminários, palestras, etc & 0,032 & 506,76 & 0,01 & 0,03 & 0,14 & 0,45 & 0,80 & 0,95 & 0,99 & 1,00 \\
\hline 2-Treinamentos técnicos ou operacionais quando surgem oportunidades & 0,032 & 507,70 & 0,01 & 0,03 & 0,14 & 0,44 & 0,79 & 0,95 & 0,99 & 1,00 \\
\hline $\begin{array}{l}\text { 4-Programas para desenvolvimento gerencial quando surgem opor- } \\
\text { tunidades }\end{array}$ & 0,029 & 525,93 & 0,01 & 0,03 & 0,10 & 0,32 & 0,67 & 0,90 & 0,97 & 0,99 \\
\hline 12-Incentivos financeiros para cursos técnicos profissionalizantes & & & 0,01 & 0,03 & & 0,32 & 0,66 & 0,89 & 0,97 & 0,99 \\
\hline 25-Avaliação de resultados obtidos nos programas informalmente & 0,030 & 529,40 & 0,00 & 0,02 & 0,08 & 0,29 & 0,65 & 0,90 & 0,98 & 0,99 \\
\hline 15-Realização de programas de treiname & 0,043 & 536,20 & 0,00 & 0,00 & 0,02 & 0,18 & 0,64 & 0,94 & 0,99 & 1,00 \\
\hline 8-Programas de qualidade & 0,027 & & 0,01 & 0,03 & 0,10 & 0,31 & 0,63 & 0,87 & 0,96 & 0,99 \\
\hline 24-Avaliaçã & 0,051 & & 0,00 & 0,00 & & & 0,63 & 0,96 & 1,00 & 1,00 \\
\hline 19-Levantamento & 0,040 & & 0,00 & 0,00 & 0,0 & & 0,61 & 0,92 & 0,99 & 1,00 \\
\hline 30-Sistema para or & 0,044 & 540,46 & 0,00 & 0,00 & 0,02 & 0,14 & 0,60 & 0,93 & 0,99 & 1,00 \\
\hline 16-Parcerias para cursos técnicos prof & 0,046 & 540,96 & 0,00 & 0,00 & 0,01 & 0,13 & 0,60 & 0,94 & 0,99 & 1,00 \\
\hline 1-Treinamentos técnicos ou operacionai & 0,045 & 541,32 & 0,00 & 0,00 & 0,02 & 0,14 & 0,60 & 0,93 & 0,99 & 1,00 \\
\hline 9-Incentivos financeiros para curso superior (gra & 0,026 & 539,89 & 0,01 & 0,03 & 0,09 & 0,26 & 0,56 & 0,82 & 0,94 & 0,98 \\
\hline 6-Oportunidades de aprendizagem e ex & 0,019 & 536,94 & 0,03 & 0,07 & 0,16 & 0,33 & 0,56 & 0,77 & 0,90 & 0,96 \\
\hline 20-Levantamento de necessidades de modo informal, não estr & 0,026 & 546,39 & 0,01 & 0,02 & 0,07 & 0,23 & 0,52 & 0,80 & 0,94 & 0,98 \\
\hline $\begin{array}{l}\text { 33-Sistema de recompensa aos colaboradores por } \\
\text { equipes }\end{array}$ & 0,029 & 547,89 & 0,00 & 0,01 & 0,06 & 0,20 & 0,52 & 0,82 & 0,95 & 0,99 \\
\hline $\begin{array}{l}\text { 3-Programas para desenvolvimento gerencial, estruturados e aprova- } \\
\text { dos em orçamento }\end{array}$ & & & 0,00 & 0,00 & 0,01 & 0,09 & 0,51 & 0,92 & 0,99 & 1,00 \\
\hline $\begin{array}{l}\text { 32-Sistema de recompensa aos colaboradores por desempenho } \\
\text { individual }\end{array}$ & 0,024 & & 0,01 & 0,02 & 0,07 & 0,21 & 0,47 & 0,75 & 0,91 & 0,97 \\
\hline $\begin{array}{l}\text { 31-Sistema formal de avaliação de desempenho com feedback aos } \\
\text { colaboradores }\end{array}$ & 0,031 & 554,36 & 0,00 & 0,01 & 0,04 & 0,16 & 0,47 & 0,80 & 0,95 & 0,99 \\
\hline $\begin{array}{l}\text { 28-Sistema de divulgação das competências necessárias para os } \\
\text { cargos }\end{array}$ & & & 0,00 & 0,00 & 0,01 & 0,08 & 0,36 & 0,78 & 0,96 & 0,99 \\
\hline 17-Parcerias para cursos de educação continuada & & & 0,00 & 0,00 & 0,01 & 0,06 & 0,35 & 0,83 & 0,98 & 1,00 \\
\hline $\begin{array}{l}\text { 7-Programa de autodesenvolvimento para funções mais complexas } \\
\text { na carreira }\end{array}$ & 0,024 & 582,08 & 0,00 & 0,01 & 0,04 & 0,12 & 0,32 & 0,60 & 0,83 & 0,94 \\
\hline 10-Incentivos financeiros para pós-graduação (especialização) & 0,019 & 592,30 & 0,01 & 0,03 & 0,06 & 0,15 & 0,31 & 0,54 & 0,75 & 0,88 \\
\hline 27-Plano de carreira estruturado & 0,025 & 606,87 & 0,00 & 0,01 & 0,02 & 0,07 & 0,20 & 0,46 & 0,75 & 0,91 \\
\hline 11-Incentivos financeiros para MBA (mestrado profissional) & 0,021 & 625,08 & 0,00 & 0,01 & 0,02 & 0,07 & 0,17 & 0,37 & 0,63 & 0,83 \\
\hline $\begin{array}{l}\text { 18-Parcerias para programas personalizados conforme } \\
\text { competências da empresa }\end{array}$ & 0,042 & 597,65 & 0,00 & 0,00 & 0,00 & 0,02 & 0,12 & 0,52 & 0,90 & 0,99 \\
\hline 13-Incentivos financeiros para mestrado/doutorado & 0,028 & 644,59 & 0,00 & 0,00 & 0,00 & 0,02 & 0,07 & 0,23 & 0,54 & 0,82 \\
\hline
\end{tabular}


níveis da EMDI. Desse modo, com uma quantidade menor de itens, alcançar-se-iam os mesmos resultados, sem prejuízo da informação, com a vantagem de economizar tempo e, conseqüentemente, recursos financeiros, na obtenção das respostas das empresas. A Figura 4 ilustra os níveis interpretados da escala com os itens mais informativos.

Na Figura 5, ilustra-se a identificação e localização das empresas na EMDI. O primeiro algarismo informa a classificação:
a) micro;
b) pequena;
c) média; e
d) grande.

Os três algarismos seguintes são o código de cada empresa. Assim, cada uma da empresas pode verificar em que nível se encontra na escala. Analisando a Figura 5, pode-se constatar que uma empresa de grande porte está localizada na EMDI abaixo de uma pequena empresa e de outra empresa de médio porte.

Fazendo uma análise global do perfil das empresas nos respectivos níveis da EMDI, têm-se, resumidamente, as seguintes características:

a) classificação das empresas (MPMG) - há empresa de grande porte localizada desde o nível inferior até o nível médio (450-500) e pequena empresa localizada no nível mais alto da EMDI (600-650);

b) tempo de atuação das empresas no ramo de negócio - observa-se a mais antiga e a mais nova, ambas localizadas no mesmo nível da escala (500-550);

c) áreas de negócios que alcançam os níveis mais altos da EMDI estabelecida com os dados levantados e interpretada para o DCH: metalúrgica, têxtil e química;

d) formação dos colaboradores - as empresas com níveis mais elevados de desempenho são também as que possuem colaboradores com maior grau de escolaridade; $\mathrm{e}$

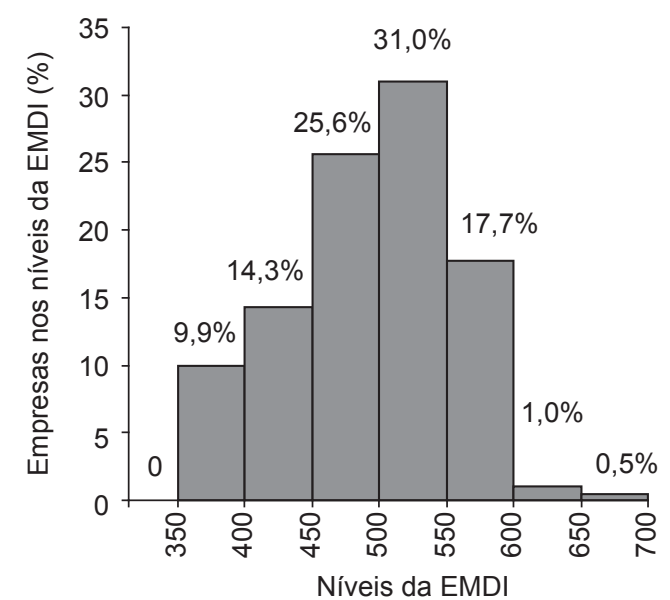

Figura 3. Histograma do percentual de empresas nos respectivos níveis da EMDI. e) função do principal responsável pela área de gestão de pessoas - os maiores percentuais são para as funções de diretoria e gerência, em todos os níveis da EMDI.

De modo geral, sabendo onde a empresa está localizada na escala, é possível conhecer quais são os intangíveis

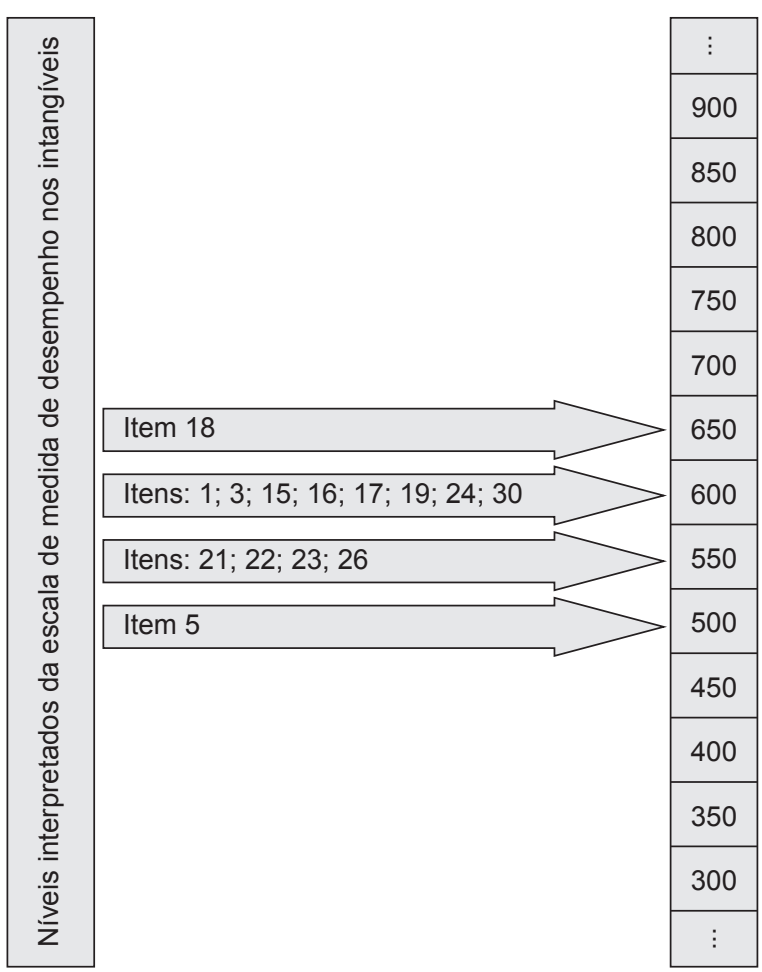

Figura 4. Níveis interpretados da EMDI e os itens mais informativos.

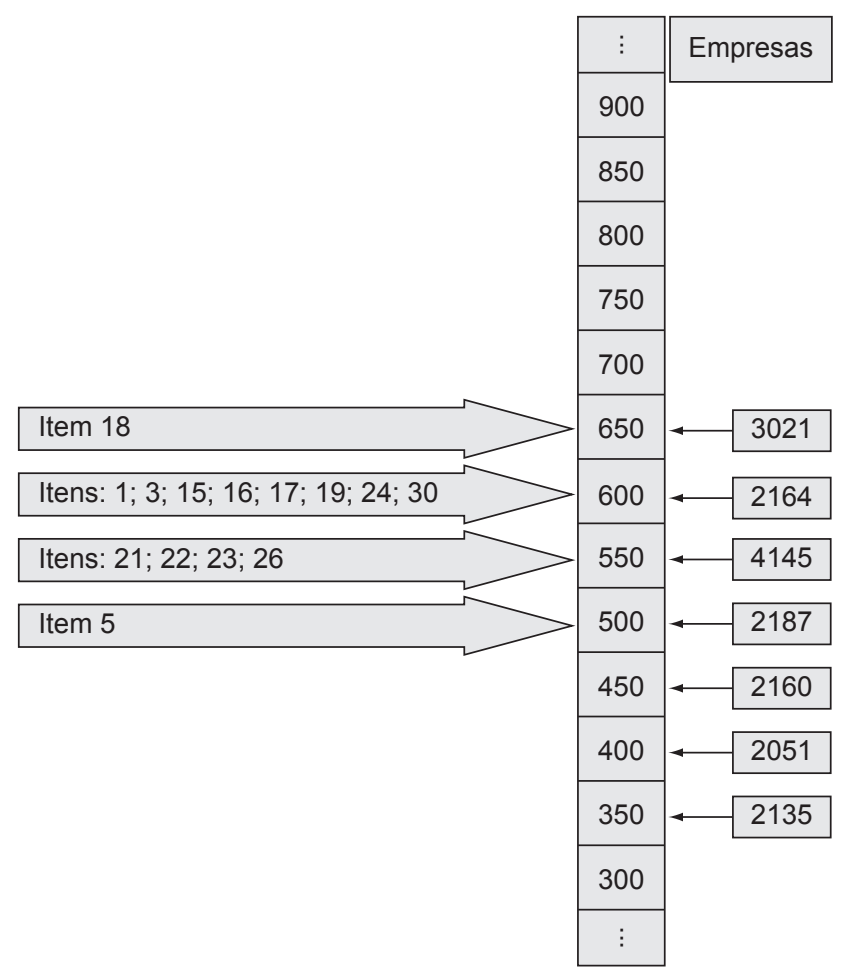

Figura 5. Exemplos de empresas e sua localização na EMDI. 
que ela possui. Um aspecto importante da avaliação diz respeito a fornecer um conhecimento detalhado dos intangíveis da empresa, os quais podem ser utilizados para apoiar as decisões dos gestores, colocando à disposição de analistas e stakeholders informações úteis em um formato padronizado. A divulgação dos intangíveis não apenas ajuda a empresa a incrementar seu valor sob a ótica de parceiros e investidores, mas também a mantê-la na orientação de seus objetivos estruturais internos, tornando-a mais eficiente, lucrativa e competitiva. Além de saber quais intangíveis a empresa possui, a EMDI possibilita avaliar sua posição em relação às demais empresas.

\section{Considerações finais}

A presente pesquisa abordou a avaliação do $\mathrm{CH}$ por meio da EMDI, possibilitando a interpretação gerencial dos intangíveis, organizados em quatro níveis de desempenho. Trabalhos futuros deverão ser realizados para outras categorias do CI, ampliando os níveis âncoras e suas interpretações, para o melhor conhecimento dos intangíveis. Gradativamente, outros itens de intangíveis podem ser estimados na mesma unidade da EMDI, constituindo um banco de itens que permitirá conduzir a avaliação dos intangíveis de modo mais fácil e com maior grau de confiança. Os parâmetros estimados, na mesma escala de medição, possibilitam acompanhar, progressivamente, tanto a inserção de novos intangíveis quanto de empresas ao banco de itens. Essa característica é importante no ambiente dinâmico da engenharia do conhecimento, no qual constantes lançamentos de sistemas, tecnologias, evolução do know-how e inovações em intangíveis requerem uma estrutura de medição flexível para acompanhar as mudanças.

Outro aspecto que esta abordagem proporciona é analisar as mudanças ocorridas devido às experiências adquiridas e aprendizagem das organizações ao longo do tempo, ou seja, acompanhar o processo de desenvolvimento de um período para outro, que pode ser anual, por exemplo. Assim, cada organização pode verificar a evolução do seu desempenho nos intangíveis de ano a ano. A cada avaliação realizada, a empresa tem um valor estimado para seu desempenho, determinado de acordo com as ações observáveis expressas nos itens dos intangíveis que possui. A sequiência de resultados dos desempenhos estimados demonstra a evolução no desenvolvimento dos intangíveis que pode ser verificada de acordo com os níveis da escala de medição. Assim, o valor do desempenho, a cada período, é localizado na EMDI, gerando um gráfico temporal. O acompanhamento da evolução nos intangíveis serve de suporte para as decisões gerenciais.

Todos esses aspectos são conhecimentos gerados que servem tanto para os gestores internos da empresa como para os demais stakeholders. Os resultados alcançados com esta pesquisa podem ser vistos como uma criação de conhecimento, porque, dos dados levantados, isto é, das respostas fornecidas pelas empresas, obtiveram-se informações que são os parâmetros estimados dos itens e dos respondentes. Essas informações, quando interpretadas, fornecem um novo conhecimento. Que conhecimento é possível ser criado com esses resultados? Alguns aspectos que podem ser relacionados à criação do conhecimento nos intangíveis são contemplados nas seguintes questões:

a) Em que nível cada uma das empresas respondentes se encontra na EMDI?

b) Quais as empresas que estão no mesmo nível da EMDI?

c) Quais as empresas que estão localizadas acima e/ou abaixo do nível médio da EMDI?

d) Como a empresa se encontra em relação às suas concorrentes?

e) Quais empresas podem servir para benchmarking?

f) Quais intangíveis são encontrados em cada uma das empresas pesquisadas?

g) Quais intangíveis são mais comuns e quais são mais raros de se encontrar nas empresas pesquisadas? Quais intangíveis a empresa necessita desenvolver para melhorar seu nível de desempenho?

As repostas a essas questões podem ser os novos conhecimentos produzidos e necessários para melhor administrar os intangíveis. A avaliação é um instrumento para a empresa identificar, em tempo hábil, de que intangíveis necessita para um planejamento estratégico e estabelecimento de objetivos adequados para seu negócio. Compreender a importância dos intangíveis constitui um fator crítico para o sucesso empresarial. Essa compreensão permite à empresa verificar onde residem seus pontos fortes e trabalhar seus pontos fracos. As avaliações possibilitam que a empresa se torne competitiva e sustentável. A avaliação oferece elementos para tomadas de decisões a respeito da capacidade de renovação, valorização e remuneração dos intangíveis. 


\title{
Intangible assessment: a human capital application
}

\begin{abstract}
This article aims at introducing a proposal for an intangible assessment implemented in human capital (HC). The development of this proposal fostered the creation of a quantitative measurement, the performance measurement scale for the intangibles (PMSI) based on the Item Response Theory (IRT) defined as the performance of organizations in intangibles. The set of items produced approaches training, development, and education and planning/assessment. The data collected from a sample of 203 companies associated to the Federation of Companies of Santa Catarina (FIESC), Brazil, allow the establishment of a four-level PMSI interpreted for the HC, which provides new knowledge about both the intangibles and the performance of companies.
\end{abstract}

Keywords: Intangible measurement. Intangible management. Intellectual capital. Human capital. Item response theory.

\section{Referências bibliográficas}

ABEYSEKERA, I.; GUTHRIE, J. Human capital reporting in a developing nation. The British Accounting Review, v. 36, n. 3, p. 251-268, 2004a.

. An empirical investigation of annual reporting trends of intellectual capital in Sri Lanka. Critical Perspectives on Accounting, v. 16, n. 3, p. 151-163, 2004b.

ALEXANDRE, J. W. C.; ANDRADE, D. F.; VASCONCELOS, A. P.; ARAUJO, A. M. S. Uma proposta de análise de um construto para a medição dos fatores críticos da gestão pela qualidade através da teoria da resposta ao item. Gestão \& Produção, v.9, n.2, p.129-141, 2002a.

ALEXANDRE, J. W. C.; ANDRADE, D. F.; VASCONCELOS, A. P.; ARAUJO, A. M. S.; BATISTA, M. J. Teoria da resposta ao item: aplicação do modelo de escala gradual na gestão pela qualidade. In: ENCONTRO NACIONAL DE ENGENHARIA DE PRODUÇÃO, 22, 2002, Curitiba. Anais..., v. 1, p. 1-20, 2002b.

ALLEE, V. The value evolution - Adressing larger implications of na intellectual capital and intangibles perspective. Journal of Intelectual Capital., v. 1, n.1, p. 17-32, 2000.

ANASTASI, A.; URBINA, S. Fidedignidade; Validade. In: Testagem psicológica. 7 ed. Porto Alegre: ARTMED, 2000. p. 84-152.

ANDRADE, D. F.; TAVARES, H. R.; VALLE, R. C. Teoria da Resposta ao Item: Conceitos e Aplicações. Caxambu: Associação Brasileira de Estatística, 2000. 154p.

ANDRIESSEN, D. IC valuation and measurement: classifying the state of the art. Journal of Intellectual Capital, v. 5, n. 2, p. 230-242, 2004a.

. Making sense of intellectual capital: designing a method for the valuation of intangibles. Boston : Elsevier ButterworthHeinemann, 2004b.

ANTUNES, M. T. P.; MARTINS, E. Gerenciando o CI: uma abordagem empírica baseada na Controladoria de grandes empresas brasileiras. In: CONGRESSO INTERNACIONAL DE CUSTOS, 9., 2005, Florianópolis. Anais eletrônicos... Florianópolis, 2005. 1 CD-ROM. (A Gestão de Custos na Era da Gestão do Conhecimento).

APRIL, K. A.; BOSMA, P.; DEDLON, D. A. IC measurement and reporting: establishing a practice in SA mining. Journal of Intellectual Capital, v. 4, n. 2, p. 165-180, 2003.
ARAUJO, L. C. G. Gestão de Pessoas: estratégias e integração organizacional. São Paulo: Atlas, 2006.

AYUSO, M. G. Intangibles: Lessons from the past and a look into the future. Journal of Intellectual Capital, v. 4, n. 4, p. 597-604, 2003.

BAKER, F. B. The Basics of Item Response Theory. 2 ed. USA: ERIC Clearinghouse on Assessment and Evaluation, 2001. Disponível em: <http://edres.org/irt/>. Acesso em: 02 jul. 2005.

BAKER, F. B.; KIM, S. Item Response Theory: parameter estimation techniques. Second edition, revised and expanded. New York: Marcel Dekker, 2004.

BONTIS, N. Intellectual capital: an exploratory study that develops measures and models. Management Decision, v. 36, n. 2, p. 63-76, 1998.

BONTIS, N.; FITZ-ENZ, J. Intellectual capital ROI: a causal map of human capital antecedents and consequents. Journal of Intellectual Capital, v. 3, n. 3, p. 223-247, 2002.

BONTIS, N.; KEOW, W. C. C.; RICHARDSON, S. Intellectual capital and business performance in Malaysian industries. Journal of Intellectual Capital, v. 1, n. 1, p. 85-100, 2000.

BOOG, G. G. Manual de treinamento e desenvolvimento. 3 ed. São Paulo: Pearson, 1999.

BORGES-ANDRADE, J. E.; ABBAD, G. S.; MOURÃO, L. Treinamento, desenvolvimento e educação em organizações e trabalho: fundamentos para gestão de pessoas. Porto Alegre: Artmed, 2006.

BOZZOLAN, S.; FAVOTTO, F.; RICCERI, F. Italian annual intellectual capital disclosure: An empirical analysis. Journal of Intellectual Capital, v. 4, n. 4, p. 543-558, 2003.

BRENNAN, N. Reporting intellectual capital in annual reports: evidence from Ireland. Accounting, Auditing \& Accountability Journal, v. 14, n. 4, p. 423-436, 2001.

BRENNAN, N.; CONNELL, B. Intellectual Capital: currente issues and policy implications. Journal of Intellectual Capital, v.1, n.3, p.206-240, 2000.

BROOKING, A. Intellectual capital: core asset for the third millennium. London: International Thomson Business Press, 1996.

CHATZKEL, J. Commentary: Moving through the crossroads. Journal of Intellectual Capital, v. 5, n. 2, p. 337-339, 2004. 
CHIAVENATO, I. Recursos humanos. 7 ed. São Paulo: Atlas, 2002. (edição compacta).

COWI. Annual Report (2000). Disponível em: <http://www.cowi. $\mathrm{dk} /$ cowi/en/topmenu/aboutcowi/>. Acesso em: 9 maio 2006.

CUMBY, J.; CONROD, J. Non-financial performance in the Canadian biotechnogy industry. Journal of Intellectual Capital. v. 2, n.3, p-261-272, 2001.

DAVENPORT, T. O. O capital humano: o que é e porque as pessoas investem nele. São Paulo: Nobel, 2001.

DESSLER, G. Treinamento e desenvolvimento de funcionários. In: Administração de recursos humanos, 2 ed. São Paulo: Prentice Hall, 2003. p.139-169.

DUTRA, J. S. Gestão de pessoas: modelo, processos, tendências e perspectivas. São Paulo: Atlas, 2002.

EDVINSSON, L.; MALONE, M. S. Intellectual capital: realizing your company's true value by finding its hidden brainpower. New York: Harper Business, 1997.

Capital Intelectual: descobrindo o valor real de sua empresa pela identificação de seus valores internos. São Paulo: Makron Books, 1998.

EMBRETSON, S. E.; REISE, S. P. Item Response Theory for Psychologists. New Jersey: Lawrence Erlbaum Associates, 2000.

ENGSTRÖM, T. E. J.; WESTNES, P.; WESTNES, S. F. Evaluating intellectual capital in the hotel industry. Journal of Intellectual Capital, v. 4, n. 3, p. 287-303, 2003.

FITZ-ENZ, J. Retorno do investimento em capital humano: medindo o valor econômico do desempenho dos funcionários. São Paulo: Makron Books Ltda, 2001.

GUTHRIE, J.; PETTY, R. Are companies thinking smart? Australian CPA, v. 70, n. 6, p. 62-64, 2000.

HAMBLETON, R. K.; SWAMINATHAN, H.; ROGERS, H. J. Fundamentals of item response theory. Newbury Park, CA: Sage, 1991.

KAUFMANN, L.; SCHNEIDER, Y. Intangibles: A synthesis of current research. Journal of Intellectual Capital, v. 5, n. 3, p. 366-388, 2004.

KAYO, E. K. A estrutura de capital e o risco das empresas tangível e intangível-intensivas: uma contribuição ao estudo da valoração de empresas. São Paulo, 2002. 110 f. Tese -(Doutorado em Administração), Faculdade de Economia, Administração e Contabilidade, Universidade de São Paulo USP.

KOCH, G. R.; LEITNER, K. H. Measuring and reporting intangible assets and results in European Contract Research Organization. In: OECD Conference Benchmarking IndustrySciennce Relationships, October 16-17, 2000, Berlin, Germany. Disponível em: <www.systemforschung.arcs.ac.at/publik/ fultext>. Acesso em: 09 ago. 2005.

LIEBOWITZ, J.; SUEN, C. Y. Developing knowledge management metrics for measuring intellectual capital. Journal of Intellectual Capital, v. 1, n.1, p. 54-67, 2000.

MARR, B.; CHATZKEL, J. Intellectual capital at the crossroads: managing, measuring, and reporting of IC. Journal of Intellectual Capital, v. 5, n. 2, p. 224-229, 2004.

MILKOVICH, G. T.; BOUDREAU, J. W. Treinamento. In: Administração de recursos humanos. São Paulo: Atlas, 2000. p. 337-376.

NUNNALLY, J. C. Psychometric theory. Nova York: McGrawHill, 1978.

OSTINI, R.; NERING, M. L. Polytomous item response theory models. California: Sage Publications, 2006.
PABLOS, P. O. Evidence of intellectual capital measurement from Asia, Europe and the Middle East. Journal of Intellectual Capital, v. 3, n. 3, p. 287-302, 2002.

Intellectual capital reporting in Spain: a comparative view. Journal of Intellectual Capital, v. 4, n. 1, p. 61-81, 2003.

PADOVEZE, C. L. Aspectos da gestão econômica do capital humano. Revista de Contabilidade do CRC-SP, São Paulo, n.14, dez., 2000.

PASQUALI, L. Psicometria: teoria e aplicações. Brasília: Editora Universidade de Brasília, 1997.

Princípios de elaboração de escalas psicológicas. Revista Psiquiatria de Clínica, v. 25, n. 5, p. 206-213, 1998. Disponível em: <http://www.hcnet.usp.br/ipq/revista/r255/conc255a. htm.>. Acesso em: 10 maio 2005.

Psicometria: teoria dos testes na psicologia e na educação. Petrópolis, RJ : Vozes, 2003.

PETTY, R.; GUTHRIE, J. Intellectual capital literature overview: measurement, reporting and management. Journal of Intellectual Capital, v. 1, n. 2, p. 155-176, 2000.

ROOS, J. et al. Intellectual capital: navigating in the new business landscape. New York: New York University Press, 1997.

ROOS, G. An Intellectual Capital Primer. Centre for Business Performance. Cranfield University, 2003. Disponível em: <http://www.euintangibles.net/library/localfiles/Roos_ AnIntellectualCapitalPrimer.PDF>. Acesso em: 9 ago. 2005.

ROOS, G.; PIKE, S.; FERNSTRÖM, L. Valuation and reporting of intangibles - state of the art in 2004. Int. J. Learning and Intellectual Capital. Disponível em: <http://www. globalaccesspartners.org/eventkc.htm>. Acesso em: 6 set. 2005.

SOARES, T. M. Utilização da teoria da resposta ao item na produção de indicadores sócio-econômicos. Pesquisa Opereracional, v. 25, n. 1, 2005. Disponível em: <http:// www.scielo.br/scielo.php?script=sci_arttext\&pid=S010174382005000100006\&lng=en\&nrm=iso >. Acesso em: 13 Feb 2007. Pré-publicação. doi: 10.1590/S010174382005000100006

STEWART, T. A. Intellectual Capital: the new wealth of organizations. New York: Doubleday/Currency, 1997.

Capital Intelectual: a nova vantagem competitiva das empresas. Rio de Janeiro : Campus, 1998.

A riqueza do conhecimento: o CI e a nova organização. Rio de Janeiro : Campus, 2002.

STONER, J. A.; FREEMAN, R. E. Administração de recursos humanos. In: Administração. 5 ed. Rio de Janeiro: LTC, 1999. p. 274-296.

SVEIBY, K. E. The new organizational wealth: managing \& measuring knowledge-based assets. San Francisco: BerrettKoehler Publishers, 1997.

The invisible balance sheet. Disponível em: <http:// www.sveiby.com/articles/InvisibleBalance.html>. Acesso em: 08 set 2005

A nova riqueza das organizações: gerenciando e avaliando patrimônios de conhecimento. Rio do Janeiro: Campus, 1998.

Methods for Measuring Intangible Assets. Disponível em: <http://www.sveiby.com/articles/IntangibleMethods.htm>. Acesso em: 08 set 2005.

TSAN, W.; CHANG, C. Intellectual capital system interaction in Taiwan. Journal of Intellectual Capital, v. 6, n. 2, p. 285-298, 2005. 
VAN DER LINDEN, W. J.; HAMBLETON, R. K. (Eds.). Handbook of Modern Item Response Theory. Springer, New York: Springer-Verlag, 1997.

VARGAS, V. C. C. Medida padronizada para avaliação de intangíveis organizacionais por meio da teoria da resposta ao item. Florianópolis, 2007. 207 f. Tese - (Doutorado em Engenharia de Produção), Programa de Pós-Graduação em
Engenharia de Produção, Universidade Federal de Santa Catarina - UFSC.

WANG, W.; CHANG, C. Intellectual capital and performance in causal models: Evidence from the information technology industry in Taiwan. Journal of Intellectual Capital, v. 6, n. 2, p. 222-236, 2005.

\section{Apêndice}
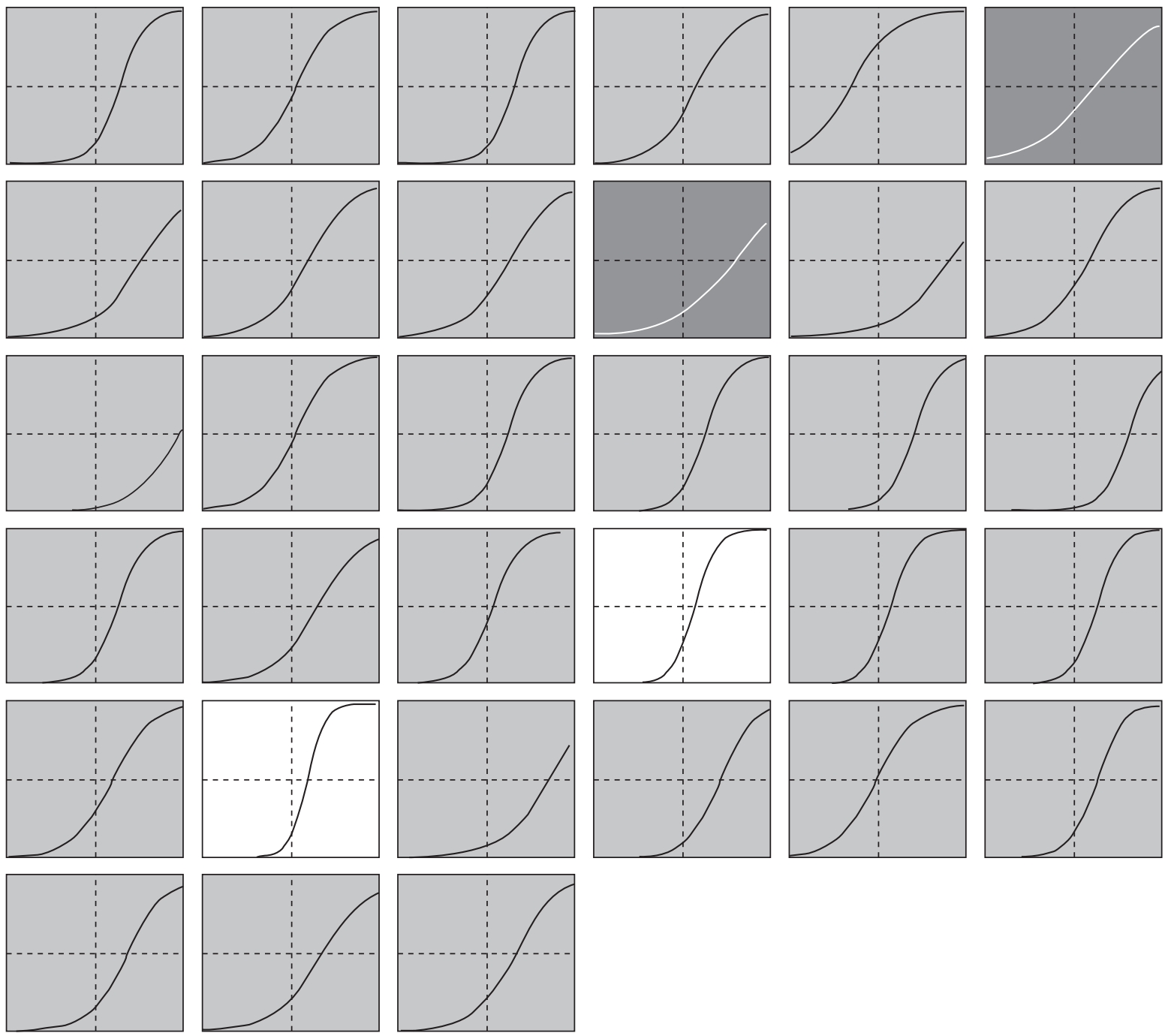

$7-12$
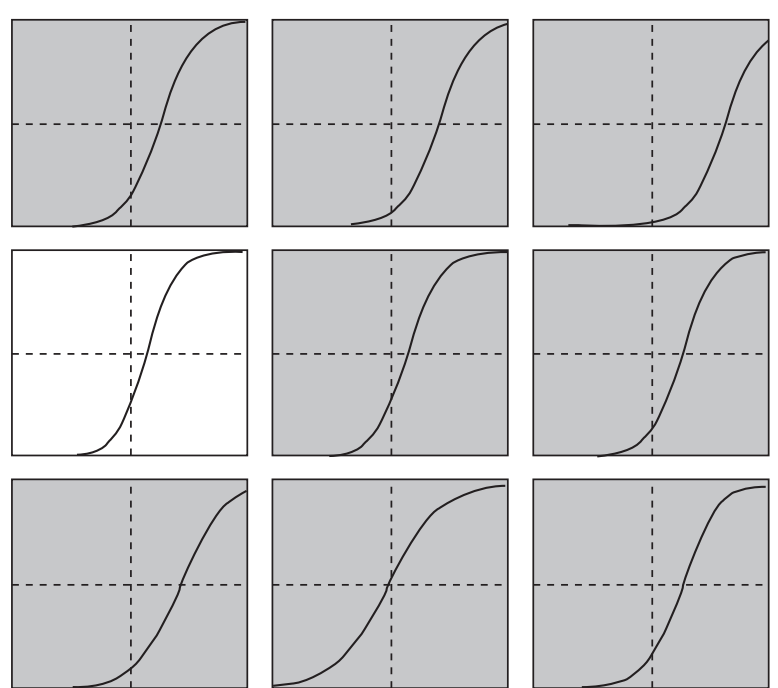

$25-30$

$31-33$

Figura 1. Curvas características dos itens - CCIs. 


\section{Sobre os autores}

\section{Vera do Carmo Comparsi de Vargas}

Universidade Federal de Santa Catarina - UFSC,

Centro Tecnológico, Campus Universitário, Trindade, CEP 88040-900, Florianópolis, SC, Brasil, e-mail: veradocarmo@gmail.com

\section{Paulo Maurício Selig}

Departamento de Engenharia de Produção, Universidade Federal de Santa Catarina - UFSC, Centro Tecnológico, Campus Universitário, Trindade, CEP 88040-900, Florianópolis, SC, Brasil, e-mail: selig@egc.ufsc.br

\section{Dalton Francisco de Andrade}

Departamento de Informática e Estatística, Universidade Federal de Santa Catarina - UFSC Centro Tecnológico, Campus Universitário, Trindade, CEP 88040-900, Florianópolis, SC, Brasil, e-mail: dandrade @ inf.ufsc.br

\section{José Luis Duarte Ribeiro}

Programa de Pós-Graduação em Engenharia de Produção, Universidade Federal do Rio Grando do Sul - UFRGS, Praça Argentina, 9, sala LOPP, CEP 90040-020, Porto Alegre, RS, Brasil, e-mail: ribeiro@ producao.ufrgs.br

Agradecimentos: Aos revisores e demais colaboradores da Gestão \& Produção pela dedicação e cooperação prestadas nas diversas etapas da publicação deste artigo. 